\title{
An alternative method for the determination of estrogens in surface water and wastewater treatment plant effluent using pre-column trimethylsilyl derivatization and gas chromatography/mass spectrometry
}

\author{
Yiqi Zhou • Jun Zhou • Yiping Xu • \\ Jinmiao Zha $\cdot$ Mei Ma $\cdot$ Zijian Wang
}

Received: 21 April 2008 / Accepted: 11 September 2008 / Published online: 21 October 2008

(C) Springer Science + Business Media B.V. 2008

\begin{abstract}
A procedure using pre-column trimethylsilyl derivatization and gas chromatography/ mass spectrometry (GC/MS) was developed and applied in determining trace estrogens in complex matrix. Main conditions were optimized, including $\mathrm{pH}$ value, salinity of water sample, elution reagents, clean procedure, derivative solvent and temperature. The optimized method was used to determine steroid estrogens in surface water and effluents of wastewater treatment plant (WWTP). Low detection limits of $0.01,0.03,0.03,0.07,0.09$ and $0.13 \mathrm{ng} / \mathrm{l}$ for DES, E1, E2, EE2, E3 and $\mathrm{E}_{\mathrm{V}}$, respectively were obtained under optimism condition. No apparent interferences appeared in chromatography in comparison with ultrapure water blank. Mean recovery ranged from $72.6 \%$ to $111.0 \%$ with relative standard deviation of
\end{abstract}

Y. Zhou · Y. Xu · J. Zha · M. Ma · Z. Wang ( $ه)$

State Key Laboratory of Environmental Aquatic

Chemistry, Research Center for Eco-Environmental

Sciences, Chinese Academy of Sciences,

P.O. Box 2871, Beijing 100085, China

e-mail: wangzj@rcees.ac.cn

J. Zhou

Beijing Drainage Group Corporation,

Beijing 100038, China

Present Address:

Z. Wang

Shuangqing Rd 18, Haidian District,

Beijing 100085, PR China
$1.1-4.6 \%$ for spiked surface water, and from $66.6 \%$ to $121.1 \%$ with relative standard deviation of $1.5-4.7 \%$ for spiked effluent of WWTP. The results suggested that the optimized method provides a robust solution for the determination of trace steroid estrogens in complex matrix.

Keywords Determination • Estrogen •

Derivativation - Gas chromatography mass spectrometry $\cdot$ Water

\section{Introduction}

It has been long concerned that the environmental impacts of the discharge of sewage effluents to water body. Attention in recent years has been focused on substances in sewage, which contain endocrine disrupting properties to wildlife and human (Feigelson and Henderson 1996; Graham et al. 2000; Xiao et al. 2001).

Steroid estrogens of natural and anthropogenic origin have been identified as the majority contributors to endocrine-disrupting activity in both sewage effluent and surface water (Desbrow et al. 1998; Lai et al. 2000; Solé et al. 2001). Estrogens are extremely potent compounds and estrogenic effects have been observed in laboratory studies down to $1 \mathrm{ng} / \mathrm{l}$ (Desbrow et al. 1998; Zha et al. 2008). So it is very important to determine the concentration of estrogens in environmental 
water. Considering low volatility of steroid estrogens, LC/MS (Ferguson et al. 2001; López and Barceló 2001; $\mathrm{Hu}$ et al. 2005; Cui et al. 2006) and LC/MS/MS (Zhang and Henion 1999; Baronti et al. 2000; Johnson et al. 2000; Xu et al. 2004, 2005, 2006; Maurício et al. 2006; Matejicek et al. 2007) methods have recently been developed for the determination of these estrogenic compounds. However, at present, the application of LC/MS and LC/MS/MS in environmental analyses of estrogenic steroids appears to be limited for their complex operation and capital costs. Therefore, as a sensitive analysis technique for determining trace estrogens in water, GC/MS is used widely in environmental analyses (Desbrow et al. 1998; Larsson et al. 1999; Rodgers et al. 2000; Zhou et al. 2007).

It is necessary for estrogens to be derivative before analyzed by GC/MS. A range of derivatives used for the determination of the steroid estrogens has been included in a review by López and Barceló (2001). Silylanized derivatives are predominantly used to facilitate determination by GC (Alda and Barceló 2001). Since GC/MS has been an available tool, N,O-bis(trimethylsily) trifluoroacetamide (BATFA) and $N$-methyl$N$ (trimethylsily)trifluoroacetamide (MSTFA) are widely used in the derivatization of estrogenic steroids by reason of its facile and low cost, which leads to the formation of trimethylsily derivative (Xiao et al. 2001; Jeannot et al. 2002; Zuo and Zhang 2005; Zhou et al. 2007). However, a great deal of research has recently reported that formation of multiple trimethylsilyl derivatives in the derivatization of $17 \alpha$-ethinylestradiol with BSTFA or MSTFA followed by gas chromatographymass spectrometry determination (Shareef et al. 2004; Zuo and Zhang 2005; Zhou et al. 2007). Fortunately, it has been found that it is an effective solution by adding trimethylsilylimidaz (TMSI) in BSTFA or MSTFA reagent (Zhou et al. 2007) or using pyridine as derivatization solvent (Zuo and Zhang 2005). Even so, the determination of trace estrogens in complex matrix such as effluents of WWTP is still a challenge for environmental monitoring.

A pre-column trimethylsilyl derivatization and gas chromatography/mass spectrometry method for the determination of estrogens had been built in our previous research (Zhou et al. 2007). In order to realize much lower detection limit and higher recovery for environmental water sample, in this study, the pretreatment conditions were optimized to assure better recovery and less matrix disruptor, and the conditions of derivatization were modified to enhance sensitivity. Based on the development of the previously proposed method, a more sensitive and precise method was built.

\section{Materials and methods}

Chemicals and materials

All solvents were of HPLC grade, purchased from J.T. Baker (Philipsburg, NJ, USA). Derivatization reagents, BSTFA+1\%TMCS and TMSI, were both purchased from Aldrich (Milwaukee, WI, USA). Estrogen standards, including diethylstilbestrol (DES), estrone (E1), 17- $\beta$-estradiol (E2), ethinylestradiol (EE2), estriol (E3) and estradiol-17-valerate $\left(\mathrm{E}_{\mathrm{V}}\right)$, were all obtained from Aldrich (Milwaukee, WI, USA), whose structures and physicochemical properties were shown in Table 1. Surrogate standard $17-\beta$-estradiol$16,16,17-d_{3}\left(\mathrm{E} 2-d_{3}\right)$ was produced by $\mathrm{C} / \mathrm{D} / \mathrm{N}$ Isotopes (Montreal, Canada). Pyrene- $d_{10}$ obtained from Supelco Inc. (Bellefonte, PA, USA) was used as the internal standard (IS). Anhydrous sodium sulfate was purchased from Beijing chemical plant (Beijing, China) and roasted at $450^{\circ} \mathrm{C}$ for $12 \mathrm{~h}$ before used. Hydrochloric acid and sodium hydroxide were purchased from Beijing chemical plant (Beijing, China). Stock standard solutions were prepared by dissolving solid standard in methanol. Calibration standards were evaporated to dryness under a gentle flow of nitrogen. Then $80 \mu$ derivative reagent BSTFA $+1 \%$ TMCS + $0.5 \%$ TMSI was added and diluted to $200 \mu \mathrm{l}$ using hexane, and reacted for $30 \mathrm{~min}$ at air bath of $40^{\circ} \mathrm{C}$.

Silica gel (60/200 mesh, ultra pure) and neutral aluminum oxide (50/200 mesh, ultra pure), which were obtained from Acros Organics (New Jersey, USA), heated at $180^{\circ} \mathrm{C}$ and $250^{\circ} \mathrm{C}$ for $12 \mathrm{hr}$, respectively, and then both cooled in a desiccator and de-activated with $3 \%$ of deionized (DI) water. The Oasis HLB cartridge $(6 \mathrm{cc}$, $500 \mathrm{mg}$ ) was purchased from Waters Corp. 
Table 1 Structure and physico-chemical properties of analytes

\begin{tabular}{|c|c|c|c|c|c|c|c|c|c|}
\hline Compound & Structure & Abbreviation & $\begin{array}{l}\text { CAS } \\
\text { number }\end{array}$ & $\begin{array}{l}\text { Molecular } \\
\text { weight }^{\text {a }}\end{array}$ & $\begin{array}{l}\text { Water } \\
\text { solubility } \\
(\mathrm{mg} / \mathrm{l})\end{array}$ & $\log$ ow $^{a}$ & $\begin{array}{l}\text { Vapor pressure } \\
(\mathrm{mm} \mathrm{Hg})\end{array}$ & $\begin{array}{l}\text { Henry's law } \\
\text { constant }^{\text {a }} \\
\text { (atm-m }{ }^{3} / \text { mole) }\end{array}$ & $\mathrm{p} K \mathrm{a}^{\mathrm{b}}$ \\
\hline $\begin{array}{l}\text { Diethylstilb } \\
\text { estrol }\end{array}$ & & DES & $\begin{array}{c}000056- \\
53-1\end{array}$ & 268.36 & 12 & 5.07 & $1.41 \mathrm{E}-008$ & 5.8E-012 & na \\
\hline Estrone & & $\mathrm{E}_{1}$ & $\begin{array}{c}000053- \\
16-7\end{array}$ & 270.37 & 30 & 3.13 & $1.42 \mathrm{E}-007$ & $3.8 \mathrm{E}-010$ & 10.4 \\
\hline 17ß-estadiol & & $\mathrm{E}_{2}$ & $\begin{array}{c}000050- \\
28-2\end{array}$ & 272.39 & $3.6\left(27^{\circ} \mathrm{C}\right)$ & 4.01 & $1.26 \mathrm{E}-008$ & 3.64E-011 & 10.23 \\
\hline $\begin{array}{l}\text { Ethynyl } \\
\text { estradiol }\end{array}$ & & $\mathrm{EE}_{2}$ & $\begin{array}{c}000057- \\
63-6\end{array}$ & 296.41 & $11.3\left(27^{\circ} \mathrm{C}\right)$ & 3.67 & $1.41 \mathrm{E}-008$ & 7.94E-012 & 10.21 \\
\hline Estriol & & $\mathrm{E}_{3}$ & $\begin{array}{c}000050- \\
27-1\end{array}$ & 288.39 & 441 & 2.45 & $1.97 \mathrm{E}-010$ & $1.33 \mathrm{E}-012$ & na \\
\hline $\begin{array}{l}17 \\
\text { B-estadiol } \\
\text { acetate }\end{array}$ & & Ev & na ${ }^{d}$ & 365.50 & na & $6.41^{\mathrm{c}}$ & na & na & na \\
\hline
\end{tabular}

${ }^{a}$ Refer to Kuster et al. $(2004,2005)$

${ }^{\mathrm{b}}$ Refer to Yu et al. (2004)

${ }^{\mathrm{c}}$ Refer to Lai et al. (2000)

${ }^{\mathrm{d}}$ Not available

(Milford, MASS, USA). Visi-prep ${ }^{\mathrm{TM}}$-DLSPE Vacuum Manifold with disposable flow control valve liners and a solid-phase extraction (SPE) system were purchased from Supelco Inc. (Bellefonte, PA, USA).

\section{Extraction and clarifying}

Water samples were pre-filtered using 0.8-2.0 $\mu \mathrm{m}$ APFF fiberglass filters (Millipore, Bedford, MA, USA) to eliminate particulate matter, and then they were spiked surrogate standard (E2- $\left.d_{3}\right)$. Adjust $\mathrm{pH}$ value using $6 \mathrm{~mol} / \mathrm{l}$ hydrochloric acid or $6 \mathrm{~mol} / \mathrm{l}$ sodium hydroxide before extraction. The Oasis HLB cartridge was conditioned with $5.0 \mathrm{~mL}$ tert-butyl methyl ether, $5.0 \mathrm{ml}$ methanol and $5.0 \mathrm{ml} \mathrm{DI}$ water respectively. Water sample (4.0 1) was passed through cartridge at a flow rate of $10.0 \mathrm{ml} / \mathrm{min}$. Then cartridge was dried under a gentle stream of nitrogen. The cartridge was then washed by $5.0 \mathrm{ml}$ of methanol/water $(25 / 75, v / v)$, $5 \mathrm{ml}$ DI water, $5 \mathrm{ml}$ methanol/ammonia/DI water $(10 / 2 / 88, v / v)$, then dried under a gentle stream of nitrogen. Subsequently, $10.0 \mathrm{ml}$ of organic solvent was used to elute SPE cartridge. Elution was gathered by KD concentrator and dehydrated by anhydrous sodium sulfate, then reduced to $0.5 \mathrm{ml}$ under a gentle stream of nitrogen with $40^{\circ} \mathrm{C}$ water bath.

The concentrated solution was cleaned up using column chromatography. At first, concentrated solution was subjected to a glass column (10 mm i.d.) containing $10 \mathrm{~g}$ of $1: 1$ alumina/silica gel, and $2.0 \mathrm{ml}$ of methanol/acetone (50/50) was used to wash KD concentrator. Transfer the solution to the glass column. Then $10.0 \mathrm{ml}$ organic solvent was used to elute the column. The elution was evaporated to dryness under a gentle stream of nitrogen.

\section{Derivatization and analysis}

The dry residues extracted from sample were redissolved in $100 \mu \mathrm{l}$ organic solvent, then $80 \mu \mathrm{l}$ derivative reagent BSTFA $+1 \% \mathrm{TMCS}+0.5 \% \mathrm{TMSI}$ was added and diluted to $200 \mu \mathrm{l}$. This mixture 
solution reacted in air bath at $40^{\circ} \mathrm{C}$ for $30 \mathrm{~min}$. Derivatized samples were analyzed using an Agilent 6890 gas chromatograph and 5973 quadrapole mass spectrometer equipped with a nonpolar HP-5 MS $30 \mathrm{~m} \times 0.25 \mathrm{~mm}$ capillary column with $0.25 \mu \mathrm{m}$ film (Agilent, USA). The injector was set at $300^{\circ} \mathrm{C}$, and the oven temperature was programmed at $80^{\circ} \mathrm{C}$ for $1 \mathrm{~min}$, ramped at $20^{\circ} \mathrm{C} / \mathrm{min}$ to $200^{\circ} \mathrm{C}$, then ramped at $10^{\circ} \mathrm{C} / \mathrm{min}$ to $300^{\circ} \mathrm{C}$ and maintained the temperature for $7 \mathrm{~min}$. The carrier gas was helium with a constant flow rate at $1 \mathrm{ml} / \mathrm{min}$. The mass spectrometer was operated in the electron impact ionization mode at $70 \mathrm{eV}$ with an interface temperature of $280^{\circ} \mathrm{C}$ and a source temperature of $230^{\circ} \mathrm{C}$. Positive fragment ions were analyzed over $50-550 \mathrm{~m} / \mathrm{z}$ mass range in SCAN mode for qualitative analysis. All control of GC and MS parameters and analysis of data were performed by MSD Productivity Chemstation Software Rev. D.00.00.

\section{Qualification and quantitation}

Qualitative analysis of target compounds was carried out at the basis of retention time and mass spectrum together in a full SCAN mode.

Quantitative analysis was performed in a selected ion monitoring (SIM) mode using internal standard calibration. Retention time, characteristic ions and quantitative ion of DES, E1, E2, EE2, E3, $\mathrm{E}_{\mathrm{v}}$ were shown in Table 2.

Initially, a series of injections of target compounds in the concentration range from $20 \mathrm{ng} / \mathrm{ml}$ to $10 \mu \mathrm{g} / \mathrm{ml}$ with constant internal standard $100 \mathrm{ng} / \mathrm{ml}$ were performed to determine the lin- ear concentration range. Calibration curves were performed by linear regression analysis.

\section{Method validation}

The recoveries and overall method reproducibility were determined from triplicate analyses $(\mathrm{N}=3)$ of spiked samples. Surface water and effluent of a wastewater treatment plant (WWTP) were spiked with $10 \mathrm{ng} / \mathrm{l}$ of the composite standard solution of six kinds of estrogen $24 \mathrm{~h}$ before analysis (to prevent microorganism growth, $0.5 \%$ volume methanol was added). Then the samples were analyzed by the method described above. Surface water was taken from a fish pool about $12,000 \mathrm{~m}^{2}$, which lies in Haidian district in Beijing and effluent (TOC $6.46 \mathrm{mg} / \mathrm{l}$, TSS $5.40 \mathrm{mg} / \mathrm{l}, \mathrm{pH}$ 7.28) was collected from Lugouqiao WWTP donating about $219700 \mathrm{~m}^{2}$ and designed to process 0.2 millions $\mathrm{m}^{3}$ wastewater per day, which lies in Fengtai district in Beijing.

The limit of detection (LOD) and limit of quantification (LOQ) for this method were achieved by concentrating $4 \mathrm{~L}$ water, and they were calculated as the minimum amount of a compound present in the sample that produced a signal to noise ratio of three to nine, based on an injection of a $1 \mu \mathrm{l}$ aliquot of the final $0.2 \mathrm{ml}$ extract solution.

\section{Results and discussion}

Optimization of the pre-concentration procedure

The sorbent of SPE cartridge and elution reagent were very important factors for SPE method ef-
Table 2 Parameters of quantification used for selected estrogens

IS Internal standard (pyrene- $d_{10}$ being as internal standard), $S S$ surrogate standard (17- $\beta$-estradiol-16,16,17$d_{3}$ being as surrogate standard)

\begin{tabular}{lllll}
\hline Compounds & Abbreviation & $\begin{array}{l}\text { Retention } \\
\text { time }(\mathrm{min})\end{array}$ & $\begin{array}{l}\text { Characteristic } \\
\text { ions }(\mathrm{m} / \mathrm{z})\end{array}$ & $\begin{array}{l}\text { Quantification } \\
\text { ion }(\mathrm{m} / \mathrm{z})\end{array}$ \\
\hline Internal standard & IS & 12.04 & 106,212 & 212 \\
cis-diethylstilbestrol & cis-DES & 12.65 & $412,397,383$ & 412 \\
trans-diethylstilbestrol & trans-DES & 13.47 & $412,397,383$ & 412 \\
Estrone & E1 & 15.57 & $342,218,257$ & 342 \\
$17-\beta$-estradiol & E2 & 15.99 & $285,416,129$ & 416 \\
Surrogate Standard & SS & 15.99 & 132,419 & 419 \\
17 -a-ethynylestradiol & EE2 & 16.81 & $285,425,440$ & 425 \\
Estriol & E3 & 17.42 & $129,345,504$ & 504 \\
Estradiol-17-valerate & $\mathrm{E}_{\mathrm{v}}$ & 18.97 & $428,231,244$ & 428 \\
\hline
\end{tabular}


ficiency. In previous studies, $\mathrm{C}_{18}$ SPE cartridge was applied (Ternes et al. 1999; Rodgers et al. 2000; López and Barceló 2001) due to its small interference of complex matrix sample. However, during the concentration procedure, the cartridge might be dry, which would affect the recovery efficiency. As a result, it is difficult to obtain good reproducibility using $\mathrm{C}_{18}$ cartridge. In comparison, Oasis HLB cartridge was a very good choice because of its hydrophobic and hydrophilic groups, which were more beneficial for enrichment of steroid estrogen (Benijts et al. 2004; Hernando et al. 2004; Beck et al. 2005; Peck et al. 2007).

Acidity of water sample would change the distribution of target substances between water and cartridge. It was necessary to optimize $\mathrm{pH}$ condition of the sample to achieve higher recovery of target compounds. The effect of $\mathrm{pH}$ was examined in the range of 1.3-13.4, and $50 \mathrm{ng} / \mathrm{l}$ target compounds were fortified according to estrogen composite standards. It was shown that the recovery of DES increased from $\mathrm{pH} 1.3$ to 5.0 and decreased after $\mathrm{pH} 9$ (Fig. 1a). Increasing $\mathrm{pH}$ value led to an increase recovery of $E 2$. Lower recovery of $E_{v}$ was observed for $\mathrm{pH} 5-8$. However, the recoveries of E1, EE2 and E3 were pH-independent evidently.

HLB cartridge contains hydrophobic and hydrophilic function groups, which interacted with steroid estrogen, including absorption and partition. The adjustment of water $\mathrm{pH}$ value would change the speciation of estrogens and surface property of sorbent, which would affect absorption or partition of analytes on cartridge. Table 1 suggested that the $\mathrm{p} K_{\mathrm{a}}$ of steroid estrogens was about 10.0. When $\mathrm{pH}$ value varied between 3 and 4, steroid estrogens might present at neutral form in water. These forms were beneficial for hydrophobic partitioning on cartridge. Meanwhile, when water $\mathrm{pH}$ was higher than 4 or lower than 3 , it would lead to analyte and cartridge carrying negative or positive charges respectively, which would affect the absorption of analytes on sorbent. Therefore, the $\mathrm{pH}$ condition was optimized from $\mathrm{pH} 3$ to $\mathrm{pH} 4$. Previous studies also showed that better retention could be acquired by acidified water sample (Ternes et al. 1999; Isobe et al. 2003; Quintana et al. 2004; Bila et al. 2007).

Salinity may also affect the extraction efficiency of organic pollutant by either liquid-liquid extraction (LLE) or solid phase extraction. Effect of salinity was evaluated by adding sodium chloride in this study. Sodium chloride was added 100 and $200 \mathrm{~g} / \mathrm{l}$ respectively to evaluate their effects with control. Figure $1 b$ showed that the recoveries of estrogens did not change with the concentration of sodium chloride except for E3. It was found that residual sodium chloride induced the dehydration of cartridge more difficult, though the increase concentration of sodium chloride enhanced the recovery of E3. Incomplete removal of water led to the fail of derivative reaction between steroid estrogen compounds and BSTFA. In order to re-
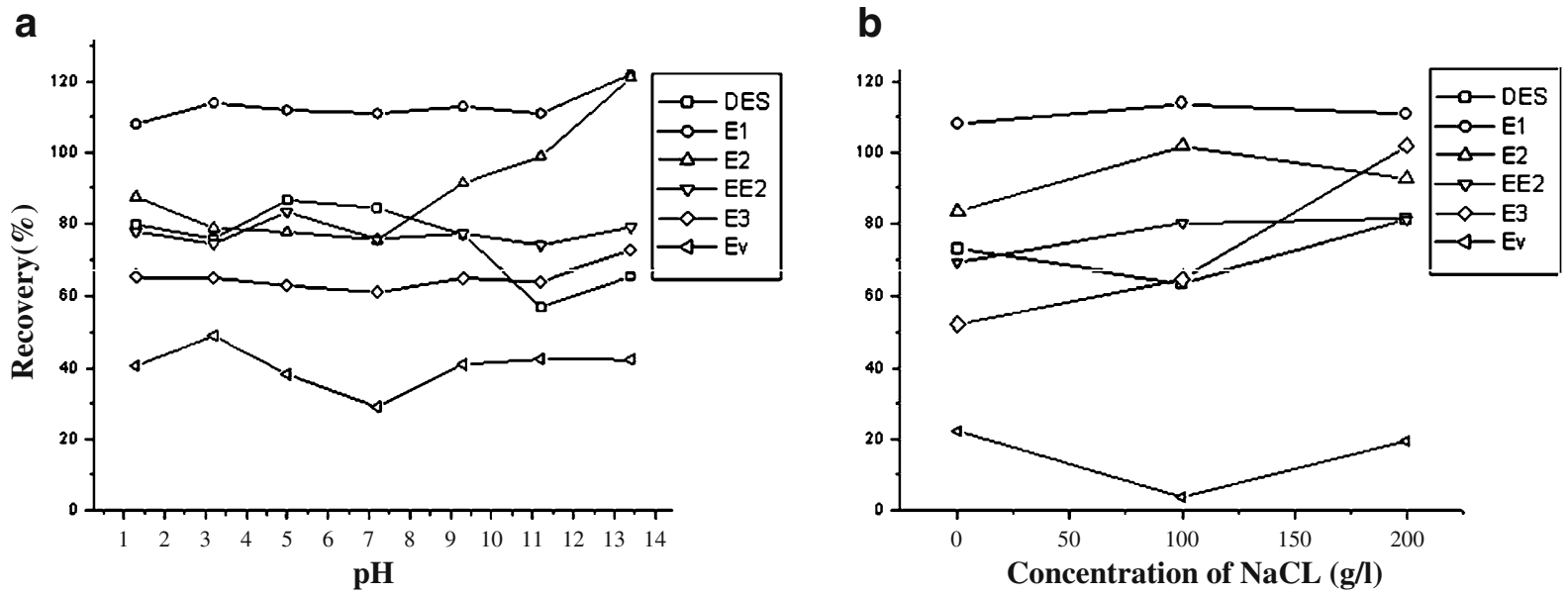

Fig. 1 Effect of $\mathbf{a} \mathrm{pH}$ and $\mathbf{b}$ salinity on the recovery of analytes (methanol was used as elution) 
Table 3 Comparison of recovery by using different elution for silicon gel filling column $(n=2)$

\begin{tabular}{|c|c|c|c|c|c|c|}
\hline \multirow[t]{2}{*}{ Solvent } & \multicolumn{6}{|l|}{ Recovery (\%) } \\
\hline & $\begin{array}{l}\mathrm{DES} \\
(\text { mean } \pm \mathrm{SD})\end{array}$ & $\begin{array}{l}\text { E1 } \\
(\text { mean } \pm \mathrm{SD})\end{array}$ & $\begin{array}{l}\text { E2 } \\
(\text { mean } \pm S D)\end{array}$ & $\begin{array}{l}\text { EE2 } \\
(\text { mean } \pm \mathrm{SD})\end{array}$ & $\begin{array}{l}\text { E3 } \\
(\text { mean } \pm S D)\end{array}$ & $\begin{array}{l}\mathrm{EV} \\
(\text { mean } \pm \mathrm{SD})\end{array}$ \\
\hline Ethyl acetate & $132 \pm 5$ & $143 \pm 3.8$ & $101 \pm 4.4$ & $104 \pm 3.2$ & 0 & $106 \pm 4.9$ \\
\hline $\begin{array}{l}\text { Acetone/hexane } \\
(65 / 35, v / v)\end{array}$ & $103 \pm 2.4$ & $122 \pm 3.2$ & $86.1 \pm 2.1$ & $85.7 \pm 2.5$ & $38.2 \pm 6.1$ & $83.9 \pm 2.2$ \\
\hline Dichloromethane & 0 & 0 & 0 & 0 & 0 & 0 \\
\hline
\end{tabular}

duce operation process and guarantee the success of derivative reaction, no variation of the salinity was performed.

HLB cartridge would capture a lot of compounds during the concentration procedure due to coextraction. The eluting reagent was optimized to ensure a better recovery of target compound and less matrix disrupting. Quintana et al. (2004) reported $70-107 \%$ of recovery could be obtained using ethyl acetate as elution, and $80-109 \%$ of recovery was realized by mixture elution of tert-butyl methyl ether and methanol $(1 / 9, v / v)$ (Jeannot et al. 2002). Therefore, comparing the two-elution strategies, mixture solvent of tert-

Abundance

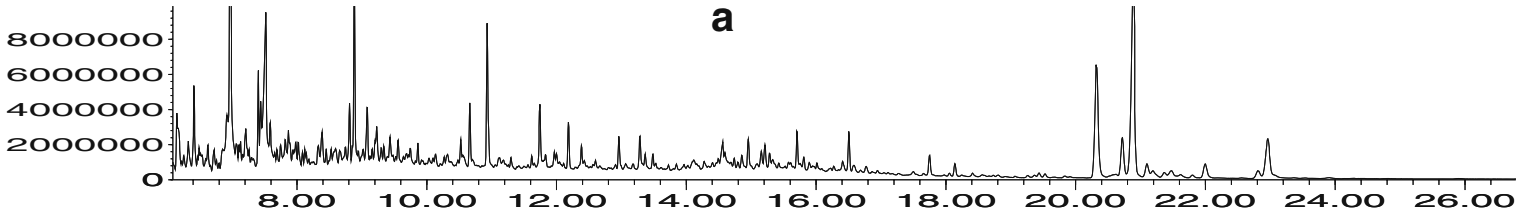

Time--

Abundance

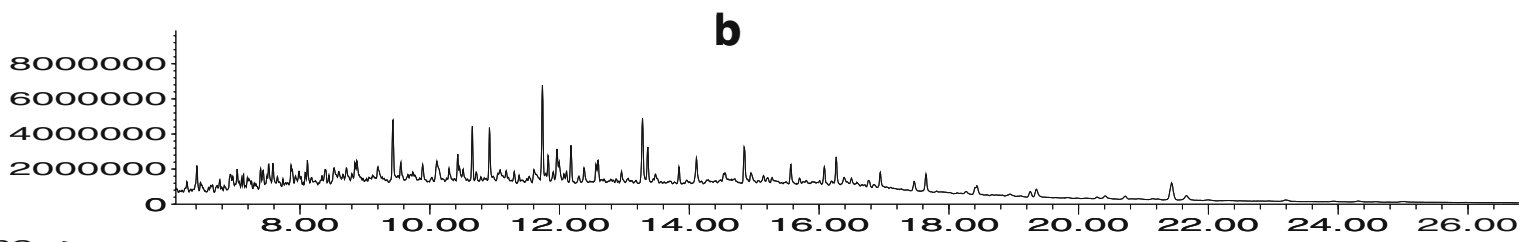

Time-->

8.0010 .0012 .0014 .0016 .0018 .0020 .0022 .0024 .0026 .00

Abundance

8000000
6000000

4000000

2000000

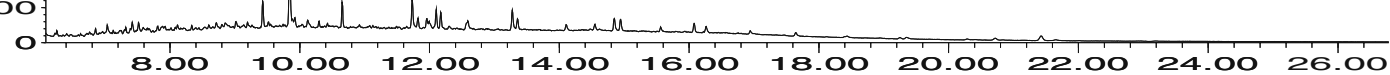

Time-->

8.0010 .0012 .0014 .00 16.00 18.0020 .0022 .0024 .0026 .00 Abundance

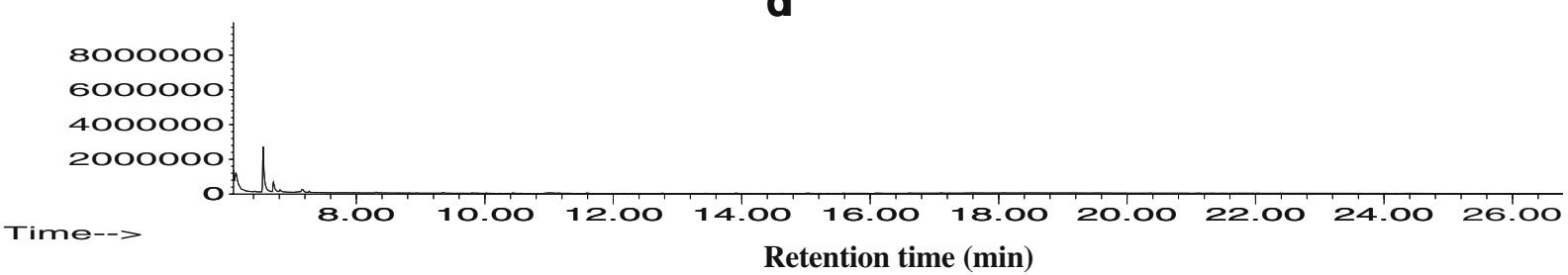

Fig. 2 GC-MS chromatograms of a crude extract, b clarified with silica gel, c clarified with silica gel and neutral aluminum oxide, $\mathbf{d}$ clarified with neutral aluminum oxide in SCAN Mode 
Table 4 Comparison of recovery using different elution for neutral aluminium oxide filling column $(n=2)$

\begin{tabular}{|c|c|c|c|c|c|c|}
\hline \multirow{2}{*}{$\begin{array}{l}\text { Solvent } \\
\text { (acetone/methanol) }\end{array}$} & \multicolumn{6}{|l|}{ Recovery (\%) } \\
\hline & $\begin{array}{l}\text { DES } \\
(\text { mean } \pm \mathrm{SD})\end{array}$ & $\begin{array}{l}\text { E1 } \\
(\text { mean } \pm \text { SD })\end{array}$ & $\begin{array}{l}\mathrm{E} 2 \\
(\text { mean } \pm \mathrm{SD})\end{array}$ & $\begin{array}{l}\text { EE2 } \\
(\text { mean } \pm \mathrm{SD})\end{array}$ & $\begin{array}{l}\text { E3 } \\
(\text { mean } \pm \mathrm{SD})\end{array}$ & $\begin{array}{l}\mathrm{EV} \\
(\text { mean } \pm \mathrm{SD})\end{array}$ \\
\hline $3 / 1$ & $27.7 \pm 3.4$ & $89.2 \pm 5.7$ & $95.0 \pm 7.3$ & $79.2 \pm 4.6$ & 0 & $89.4 \pm 5.3$ \\
\hline $1 / 1$ & $76.5 \pm 2.2$ & $118 \pm 3.5$ & $122 \pm 4.6$ & $83.2 \pm 3.1$ & $52.6 \pm 1.2$ & $93.5 \pm 4.1$ \\
\hline
\end{tabular}

butyl methyl ether/ methanol $(1 / 9, v / v)$ was selected as elution reagent in this study. The coelution was tested with two different solvents above and the results suggested that there was less coelution in tert-butyl methyl ether/ methanol $(1 / 9, v / v)$.

Optimization of the clarification procedure

The effect of sorbent $(10 \mathrm{~g})$ of cleaning column and elution reagents on recovery and clarifying efficiency were investigated in this study. And different elution solvents were selected to test silicon gel and neutral aluminum oxide. Ethyl acetate, acetone/hexane $(65 / 35, v / v)$ and dichloromethane (10 $\mathrm{ml}$ solvent) were tested for their recoveries in the silicon gel test. Table 3 showed that in the experiment of recovery efficiency that used ethyl acetate as elution, higher recoveries of $132 \pm$ $5.0 \%, 143 \pm 3.8 \%, 101 \pm 4.4 \%, 104 \pm 3.2 \%, 106 \pm$ $4.9 \%$ for DES, E1, E2, EE2, $\mathrm{E}_{v}$ respectively were obtained except for E3. Acetone/hexane (65/35, $v / v$ ) could enhance the recovery of E3 to $38.2 \pm$

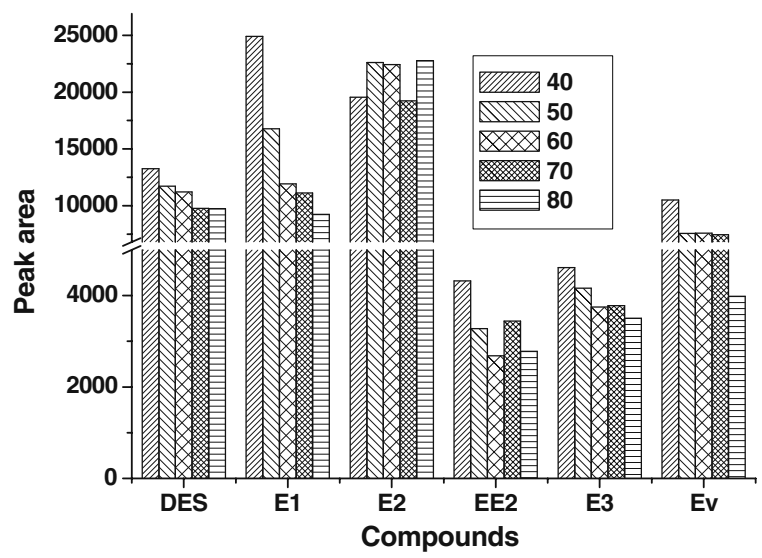

Fig. 3 Effect of the reaction temperature on peak area of analytes (hexane used as solvent and reaction half an hour)
6.1, but decreased the recoveries of E2, EE2, $E_{v}$ to $86.1 \pm 2.1 \%, 85.7 \pm 2.5 \%, 83.9 \pm 2.2 \%$. Dichloromethane could not provide good recoveries for these estrogens at all. However, as shown in Fig. 2b, the silicon gel could not remove matrix disrupting effectively.

When neutral aluminum oxide was used as sorbent, the acetone/methanol ratios of 3/1 $(v / v)$ and $1 / 1(v / v)$ were tested respectively. Table 4 suggested that acetone/methanol of $3 / 1$ could not elute E3 at all and made a lower recovery for DES $(27.7 \pm 3.4)$. When $1 / 1$ acetone/methanol was used as elution, the recovery of E3 could attain $52.6 \pm$ $1.2 \%$ and the recovery of DES, E1, E2, EE2 and $\mathrm{E}_{\mathrm{v}}$ were $76.5 \pm 2.2,118 \pm 3.5,122 \pm 4,83.2 \pm 3.1$ and $93.5 \pm 4.1$ respectively. As shown in Fig. 2d, neutral aluminum oxide could eliminate the matrix disrupting completely. The lower recoveries might be due to the strong absorption of polar estrogens on aluminum oxide.

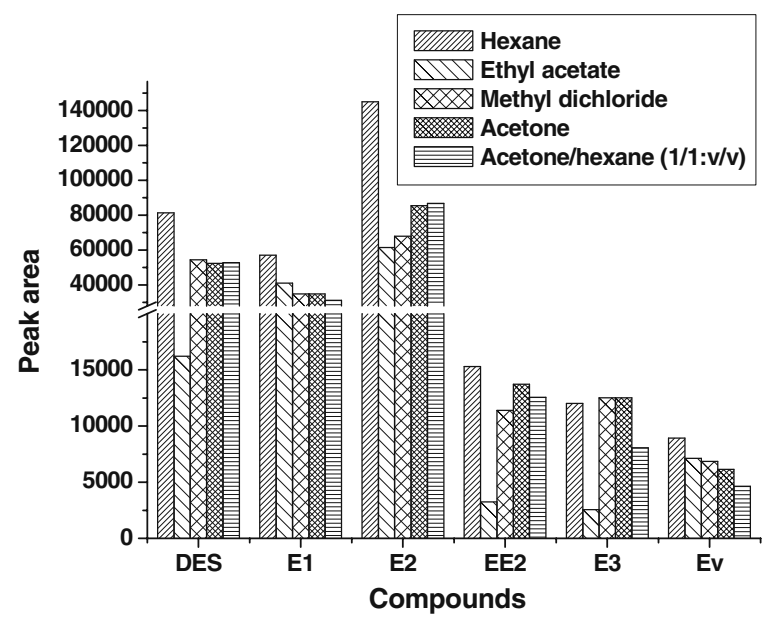

Fig. 4 Effect of reaction solvent on peak area of analytes (reaction half an hour at $40^{\circ} \mathrm{C}$ air bath) 
Fig. 5 a GC-MS

chromatograms of TMS

derivatives of analytes in

SCAN Mode (injection

$1 \mu \mathrm{l} 1000 \mathrm{ng} / \mathrm{ml}$ mixture

standard) b GC-MS

chromatograms of

trimethylsilyl (TMS)

derivatives of analytes,

surrogate and internal

standard in SIM Mode

(injection $1 \mu \mathrm{l} 50 \mathrm{ng} / \mathrm{ml}$ mixture standard)
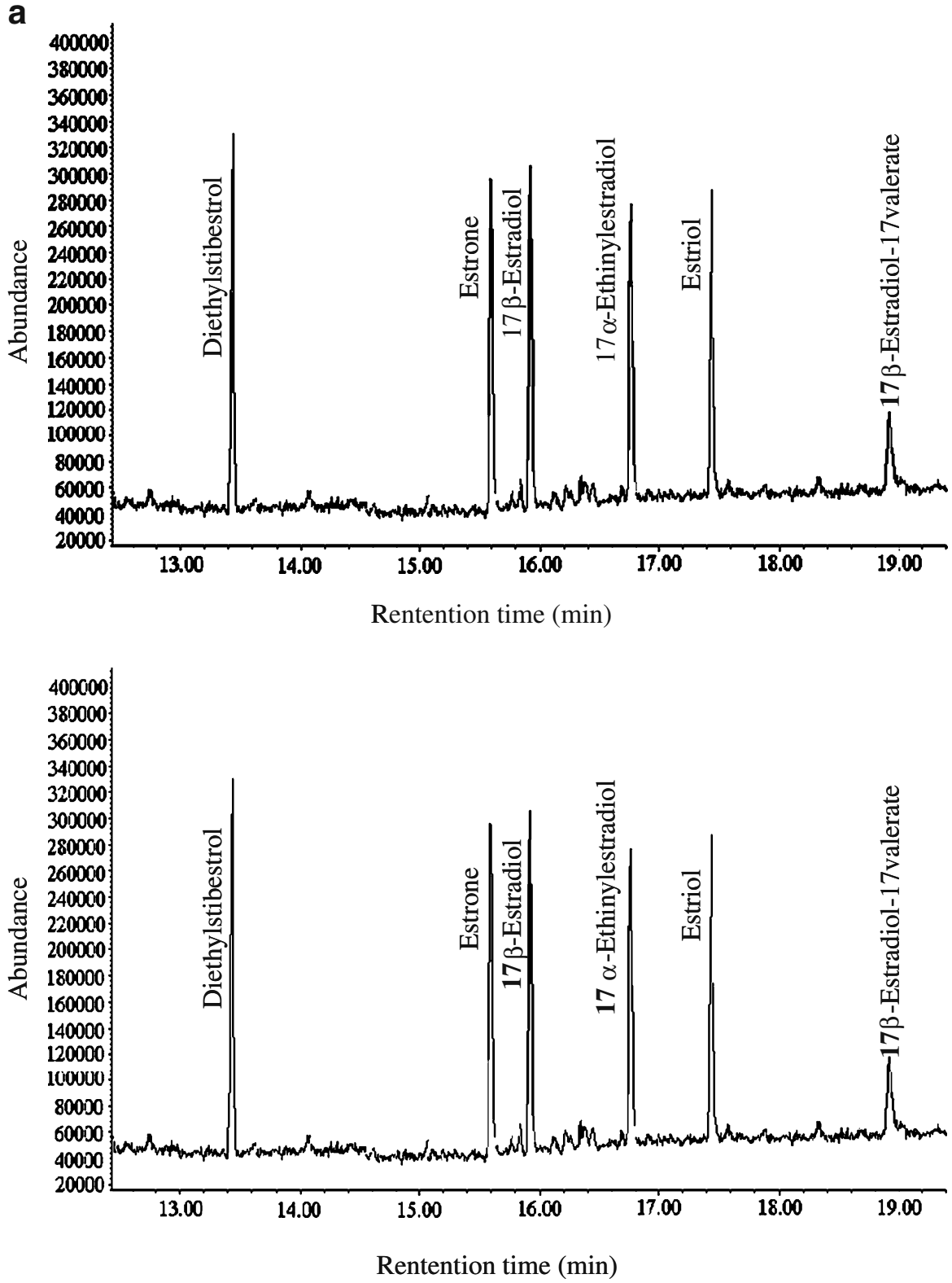

Combining the characteristics of silicon gel and neutral aluminum oxide, a cartridge with silicon gel and neutral aluminum oxide $1: 1$ as sorbent were designed. Effluent of WWTP was used to check the recovery and clarification efficiency. Higher recovery and better matrix elimination were obtained simultaneously when acetone/ methanol (1:1) was used to elute cartridge. Less disrupting peaks were found in Fig. 2c comparing with Fig. 2b, which was clarified only with silica gel. The recovery of DES, E1, E2, EE2, E3 and $\mathrm{E}_{\mathrm{v}}$ are $97.5 \pm 4.2,108 \pm 3.6,98.2 \pm 6.5,94.2 \pm 2.0$, $88.1 \pm 1.6$ and $92.6 \pm 2.8$.

Optimization of the derivative condition

It was a novel solution by adding trimethylsilylimidaz (TMSI) in BSTFA or MSTFA reagent to deal with the formation of multiple trimethylsilyl derivatives in the derivatization of $17 \alpha$-ethinylestradiol 
Fig. 5 (continued)

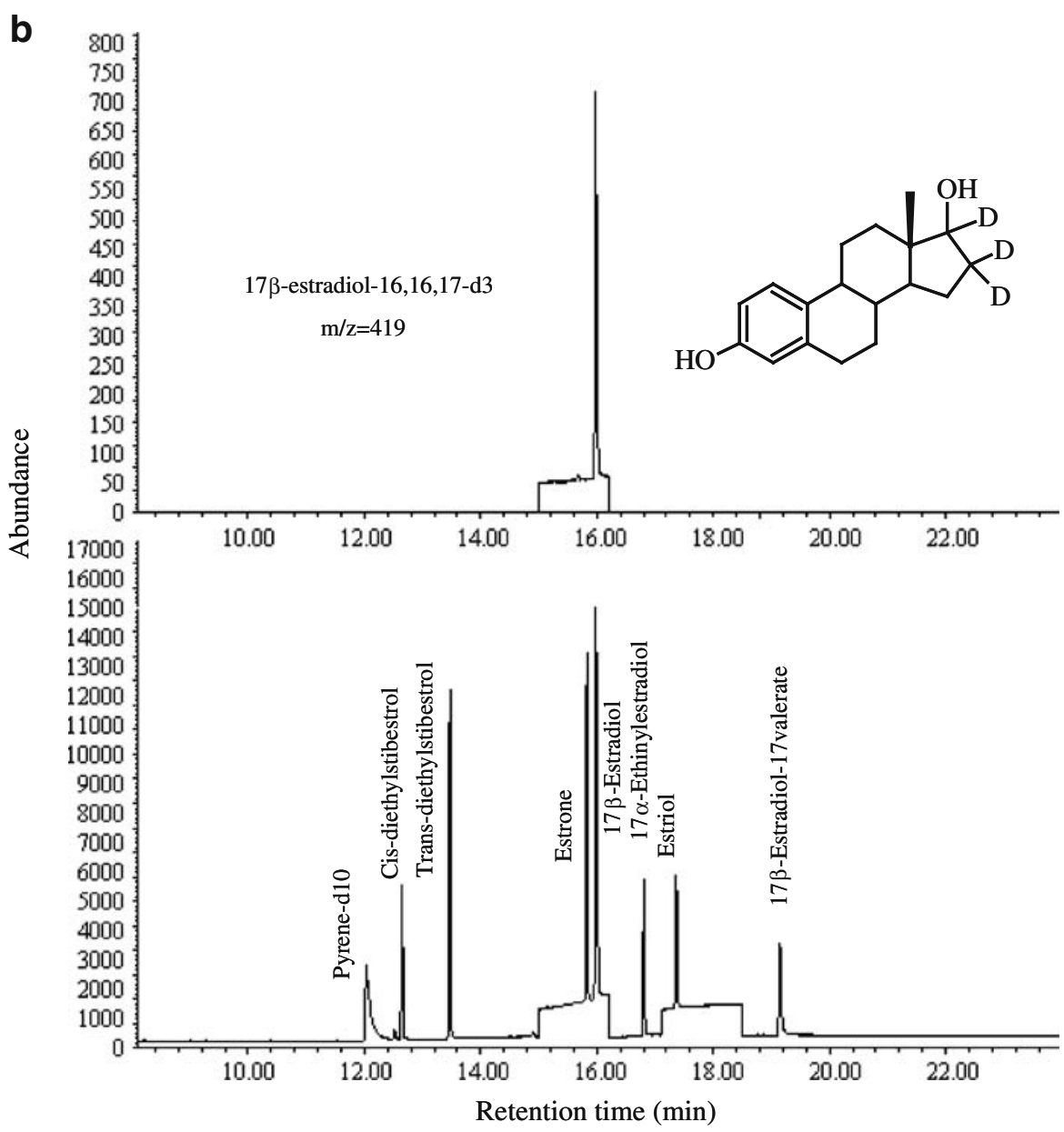

with BSTFA followed by gas chromatographymass spectrometry determination (Zhou et al. 2007). To obtain higher sensitivity and broader linearity, the effects of temperature and solvent on derivative reaction were examined. In the investigation of the effects of temperature on chromatographic peak area, hexane was chose as reaction solvent. Figure 3 showed that the peak area of analytes deceased when derivative reaction temperature increased in the range of $40^{\circ} \mathrm{C}$ to $80^{\circ} \mathrm{C}$ except for $\mathrm{E}_{2}$, which was temperatureindependent. In the experiments of effects of temperature, the greatest variation of peak area was found for $E_{1}$. The ratios of variation of peak area were about 1.36, 2.70, 1.17, 1.55, 1.31, 2.63 for DES, $E_{1}, E_{2}, E_{2}, E_{3}$ and $E_{v}$ respectively. The peak area of analytes did not change with time after half an hour reaction at $40^{\circ} \mathrm{C}$. The reaction temperature was set to $40^{\circ} \mathrm{C}$ and the sensitivity was enhanced about two times. The optimal temperature in this study was obviously lower than those that used in previous work with different derivative reagent from $60^{\circ} \mathrm{C}$ to $100^{\circ} \mathrm{C}$ (Jeannot et al. 2002; Shareef et al. 2004). Further lower temperature was not suitable for the reaction. A standard with $1,000 \mathrm{ng} / \mathrm{ml} \mathrm{EE}_{2}$ was injected to test whether undesirable TMS derivative would produced, and it was suggested that no undesirable by-products of $\mathrm{EE}_{2}$ were traced in SCAN Mode.

At $40^{\circ} \mathrm{C}$, different solvent, including hexane, ethyl acetate, dichloromethane, acetone and acetone/hexane $(1: 1, v / v)$ was tested on media effects. As shown in Fig. 4, the largest peak area of analyte was achieved when hexane was used as solvent. Ethyl acetate led to the smallest peak area for DES, EE2 and E3. Undesirable TMS derivative 
Fig. 6 Mass spectra of TMS derivative of $\mathbf{a}$ di-trimethylsilyl (TMS) diethylstilbestrol (DES), b mono-TMS estrone (E1), c di-TMS 17 $\beta$-estradiol (E2), d di-TMS

$17 \alpha$-ethinylestradiol (EE2), e tri-TMS estriol (E3), f mono-TMS 17 $\beta$-estradiol acetate $\left(\mathrm{E}_{\mathrm{v}}\right)$
$[\mathrm{M}]^{+}$

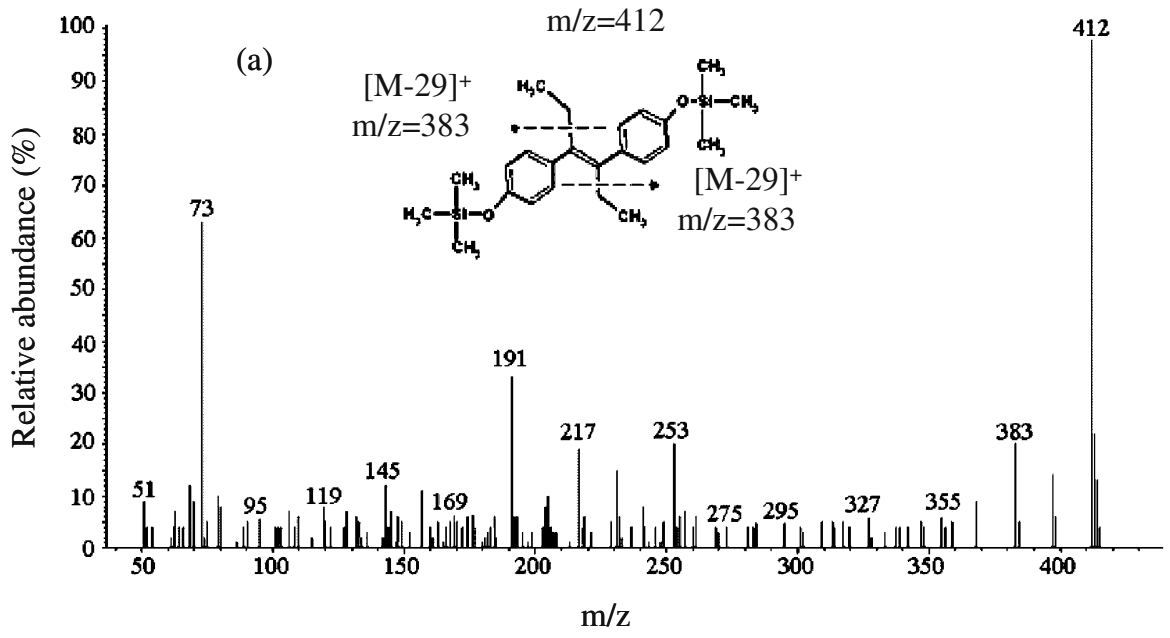

(b)
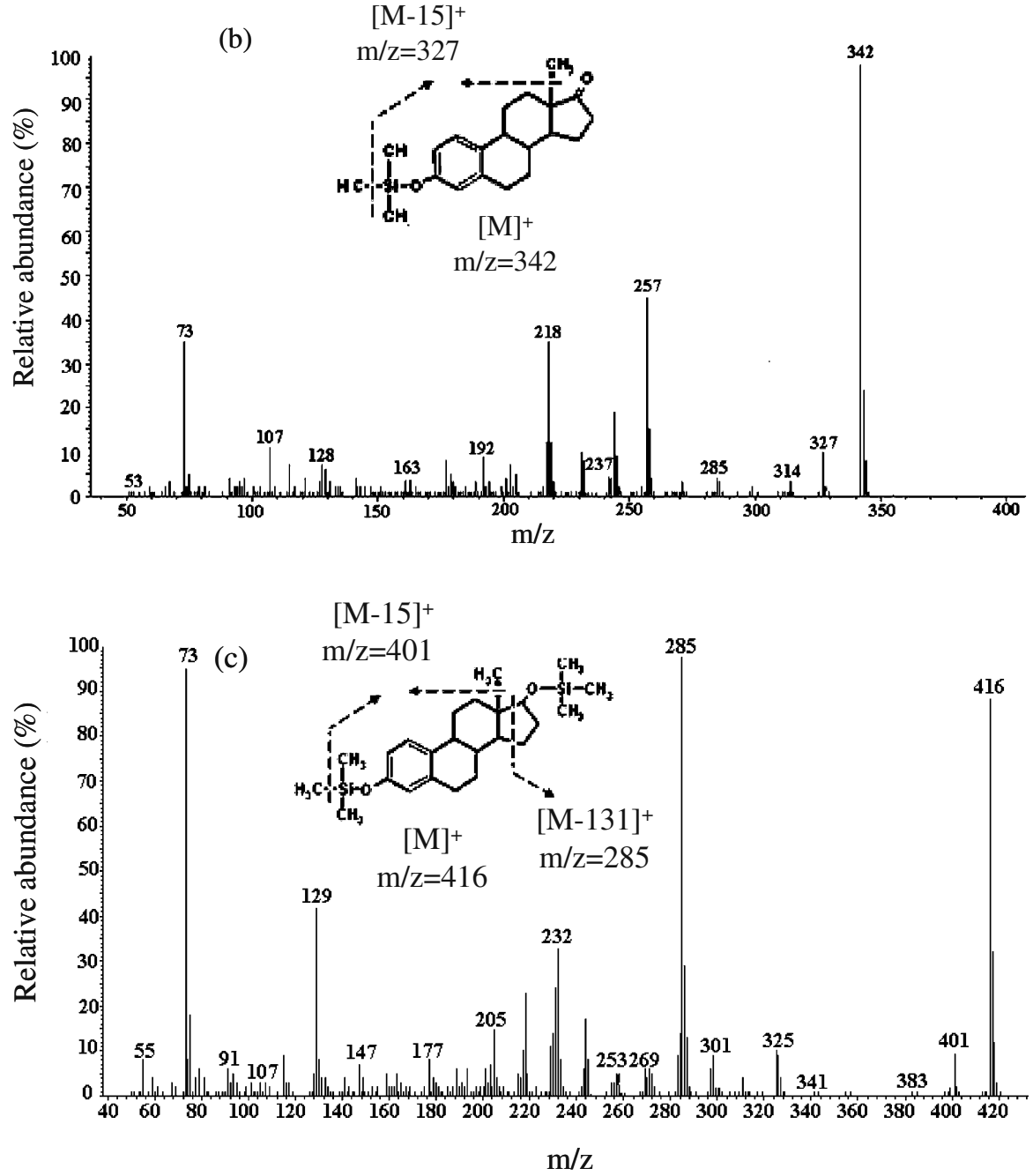
Fig. 6 (continued)
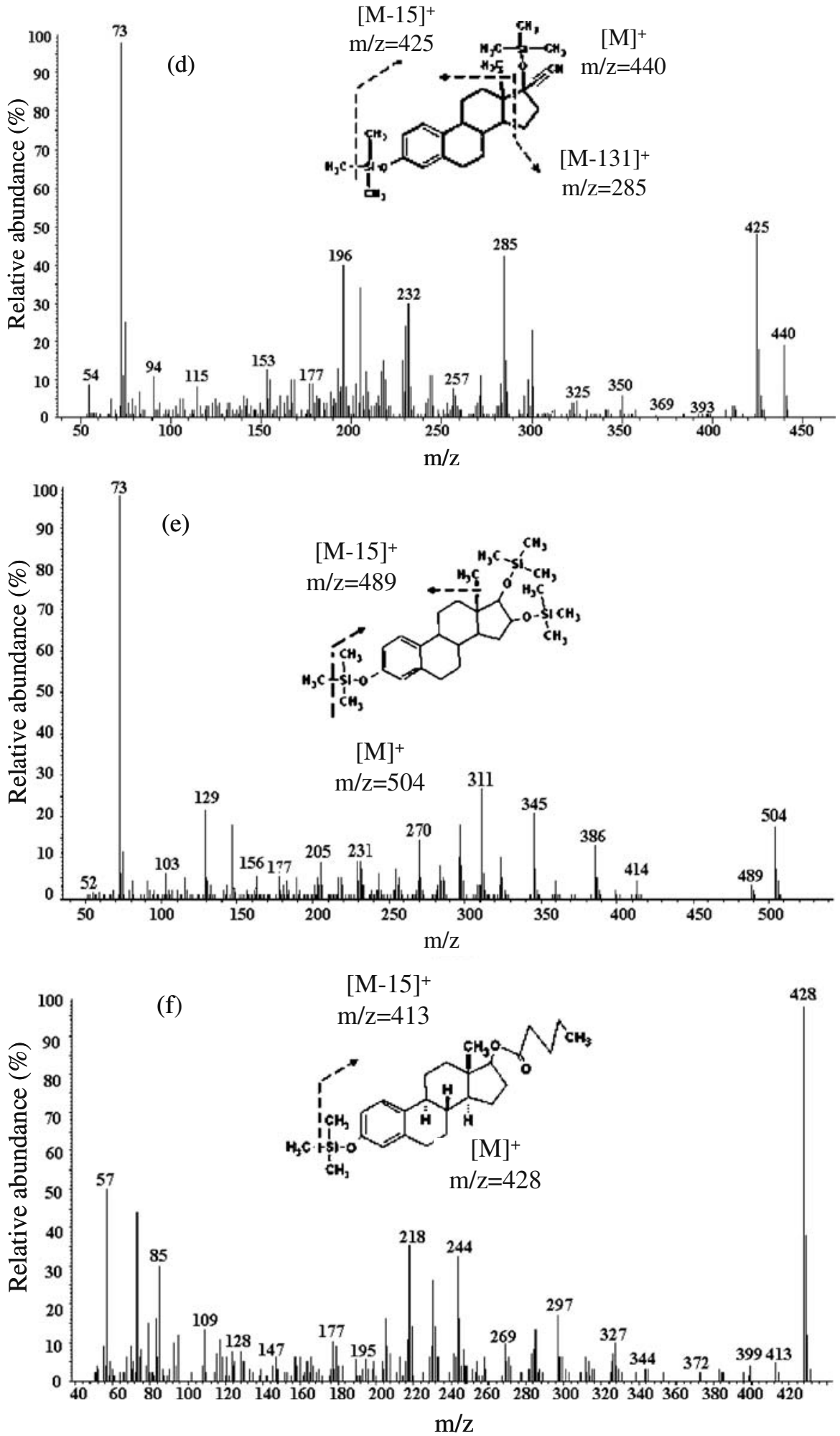
Table 5 Average recoveries and relative standard (RSD) for 6 estrogens spiked $10 \mathrm{ng} / \mathrm{l}$ in surface water and effluent of WWTP $(n=3)$

\begin{tabular}{lcllll}
\hline Estrogens & Surface water & & Effluent of WWTP & \\
\cline { 2 - 3 } & Mean recoveries (\%) & RSD (\%) & & Mean recoveries (\%) & RSD (\%) \\
\hline DES & 80.7 & 4.5 & 66.6 & 3.3 \\
E1 & 111.0 & 2.4 & & 90.4 & 4.7 \\
E2 & 81.3 & 4.4 & & 85.3 & 1.5 \\
EE2 & 107.5 & 3.7 & & 121.1 & 2.6 \\
E3 & 72.6 & 1.1 & & 87.5 & 4.3 \\
E $_{v}$ & 90.9 & 4.6 & & 74.8 & 2.1 \\
\hline
\end{tabular}

of EE2 was not present in above reactions. Therefore, hexane was selected as reaction solvent.

Method performance

According to the optimized condition, water samples were pre-filtered using 0.8-2.0 $\mu \mathrm{m}$ APFF fiberglass filters to remove particulate matter, and then were spiked surrogate standard $\left(\mathrm{E} 2-d_{3}\right)$. The $\mathrm{pH}$ value was adjusted to 3-4 using $6 \mathrm{~mol} / \mathrm{l}$ hydrochloric acid or $6 \mathrm{~mol} / \mathrm{l}$ sodium hydroxide before extraction. The Oasis HLB cartridge was conditioned with $5.0 \mathrm{~mL}$ tert-butyl methyl ether, $5.0 \mathrm{ml}$ methanol and $5.0 \mathrm{ml}$ DI water respectively. Water sample (4.0 l) was passed through cartridge at a flow rate of $10.0 \mathrm{ml} / \mathrm{min}$. Then cartridge was dried under a gentle stream of nitrogen. The cartridge was then washed by $5.0 \mathrm{ml}$ of methanol/water $(25 / 75, v / v), 5 \mathrm{ml}$ DI water, $5 \mathrm{ml}$ methanol/ammonia/DI water $(10 / 2 / 88, v / v)$, then dried under a gentle stream of nitrogen. Subsequently, $10.0 \mathrm{ml}$ of methanol/ tert-butyl methyl ether $(1 / 9, v / v)$ was used to elute SPE cartridge. Elution was gathered by KD concentrator and dehydrated by anhydrous sodium sulfate, then reduced to $0.5 \mathrm{ml}$ under a gentle stream of nitrogen with $40^{\circ} \mathrm{C}$ water bath. The concentrated solution was cleaned up using column chromatography. At first, concentrated solution was subjected to a glass column (10 mm i.d.) containing $10 \mathrm{~g}$ of $1: 1$ alumina/silica gel, and $2.0 \mathrm{ml}$ of methanol/acetone (50/50) was used to wash KD concentrator. Transfer the solution to the glass column. Then $10.0 \mathrm{ml}$ methanol/ acetone $(1 / 1, v / v)$ was used to elute the column. The elution was evaporated to dryness under a gentle stream of nitrogen. The dry residues were redissolved in $100 \mu \mathrm{l}$ hexane, then $80 \mu \mathrm{l}$ derivative reagent BSTFA $+1 \%$ TMCS + $0.5 \%$ TMSI was added and diluted to $200 \mu \mathrm{l}$. This mixture solution was reacted in air bath at $40^{\circ} \mathrm{C}$ for $30 \mathrm{~min}$ and then analyzed by GC/MS.

Figure 5 showed the chromatograms of analytes in SCAN and SIM mode. Figure 6 explained the corresponding mass spectra on detail. Good chromatography separation was realized and characteristic ion was obtained. The trimethylsilyl (TMS) derivatives of DES, E1, E2, EE2, E3 and $\mathrm{E}_{\mathrm{v}}$ were (a) di-TMS DES, (b) mono-TMS E1, (c) di-TMS E2, (d) di-TMS EE2, (e) tri-TMS E3, (f) mono-TMS $E_{\mathrm{v}}$. No undesirable TMS derivative of EE2 was found. Instead, two isomers of DES (cis-diethylstilbestrol and trans-diethylstilbestrol)

Table 6 Calibration curve, limit of detection (LOD) and limit of quantification (LOQ) for six estrogens fortified at 20, 40, $60,80,100,500,1,000 \mathrm{ng} / \mathrm{ml}$

\begin{tabular}{lllll}
\hline Compound & Calibration curve & $R^{2}$ & LOD $^{\mathrm{a}}(\mathrm{ng} / \mathrm{l})$ & $\mathrm{LOQ}^{\mathrm{b}}(\mathrm{ng} / \mathrm{l})$ \\
\hline DES & $y=4173.5 x$ & 0.9979 & 0.01 & 0.03 \\
E1 & $y=1521.6 x$ & 0.9987 & 0.03 & 0.09 \\
E2 & $y=1454.0 x$ & 0.9951 & 0.03 & 0.09 \\
EE2 & $y=948.5 x$ & 0.9968 & 0.07 & 0.21 \\
E3 & $y=558.3 x$ & 0.9981 & 0.09 & 0.27 \\
E $_{\mathrm{v}}$ & $y=343.4 x$ & 0.9981 & 0.13 & 0.39 \\
\hline
\end{tabular}

${ }^{a}$ Values estimated on a minimal $\mathrm{S} / \mathrm{N}$ of 3

${ }^{b}$ Values estimated on a minimal $\mathrm{S} / \mathrm{N}$ of 9 
Table 7 Range, mean and standard deviation (SD) in surface water and effluent of WWTP (ng/l)

nd No detection

\begin{tabular}{llllllll}
\hline Estrogens & \multicolumn{2}{l}{ Surface water } & & & \multicolumn{4}{l}{ Effluent of WWTP } \\
\cline { 2 - 3 } & Range & Mean & SD & & Range & Mean & SD \\
\hline DES & nd & - & - & & nd-0.30 & 0.15 & 0.21 \\
E1 & $1.60-2.00$ & 1.80 & 0.30 & & $1.90-3.00$ & 2.45 & 0.78 \\
E2 & $0.30-0.50$ & 0.40 & 0.10 & & nd-2.00 & 1.00 & 1.41 \\
EE2 & nd-1.60 & 0.80 & 1.10 & & $1.90-2.50$ & 2.20 & 0.42 \\
E3 & nd & - & - & & $0.60-1.90$ & 1.25 & 0.92 \\
E $_{\mathrm{v}}$ & nd & - & - & & nd & - & - \\
\hline
\end{tabular}

were presented in Fig. 5b, while only the peak of trans-DES appeared in Fig. 5a due to very small ratio of cis-DES in total DES. Calculating its concentration on the basis of the correlation of total peak area and total concentration, good linearity was observed with correlation coefficients above 0.99 for concentrations from 0 to $1000 \mathrm{ng} / \mathrm{ml}$ and a better linearity and instrument detection limit (IDL) were obtained.

The procedure was applied in spiked surface water and effluents of WWTP. Mean recovery ranged from 72.6 to $111.0 \%$ with relative standard deviation $1.1-4.6 \%$ for spiked surface water, and $66.6 \%$ to $121.1 \%$ with relative standard deviation $1.5-4.7 \%$ for spiked effluent of WWTP. Detailed results were shown in Table 5. The limit of detection (LOD) was similar with the value calculated from instrument detection limit (IDL). LOD of analytes could even attain $0.01 \mathrm{ng} / \mathrm{l}$ (Table 6).

The method was applied to determine estrogens concentrations in surface water and wastewater samples. The mean concentrations of E1, E2, and EE2 in surface water ranged from 1.6 to $2.0,0.3$ to 0.5 , no detection (nd) to $1.6 \mathrm{ng} / \mathrm{l}$, respectively. No DES, E3 and $\mathrm{E}_{\mathrm{v}}$ were detected in surface water. The mean concentrations of DES, E1, E2, EE2 and E3 in effluents of WWTP ranged from nd to $3.0,1.9$ to 3.0 , nd to $2.0,1.9$ to 2.5 and 0.6 to $1.9 \mathrm{ng} / \mathrm{l}$ respectively. Detail referred to Table 7. Previous study widely reported the presence of steroid estrogens in surface water and effluent of WWTPs. In river water sample, concentration of E1, E2 and EE2 were changed from nd to $74 \mathrm{ng} / \mathrm{l}$ in United Kingdom (Fawell et al. 2001), Italy (Baronti et al. 2000) and China (Chen et al. 2007). In effluent of WWTPs, common detected value were nd to 82 , nd to 64 , nd to 42 and 0.4 to $39.1 \mathrm{ng} / \mathrm{lfor} \mathrm{E} 1, \mathrm{E} 2, \mathrm{EE} 2$ and E3 in Netherlands (Vethaak et al. 2005), Italy (Baronti et al. 2000), U.K. (Desbrow et al. 1998; Johnson and Sumpter 2001), Germany and Canada (Ternes et al. 1999), Sweden (Larsson et al. 1999), Japan (Nakada et al. 2007) and China (Wang et al. 2005; Chen et al. 2007; Sun et al. 2008). Our results in this study were within the range of previous report.

\section{Conclusions}

An optimized condition for determining trace estrogen in surface water and wastewater treatment plant effluent had been obtained in the current work. The $\mathrm{pH}$ value of water sample was adjusted to $3-4$, and salinity was not altered. HLB cartridge was conditioned with $10 \mathrm{~mL}$ methanol/ tert-butyl methyl ether $(1 / 9, v / v)$. Extract was clarified using a glass column (10 mm i.d.) containing $10 \mathrm{~g}$ of 1:1 alumina/silica gel with $10 \mathrm{~mL}$ acetone/methanol elution, then dried under gentle nitrogen. The dried residuals were derivatized by TMSI and BSTFA in hexane solvent at $40^{\circ} \mathrm{C}$ in air bath, then analyzed by GC/MS.

Correlation coefficient of 0.9951 to 0.9987 was determined. Detection limits were 0.01, 0.03, 0.03, 0.07, 0.09, $0.13 \mathrm{ng} \mathrm{L}^{-1}$ for DES, E1, E2, EE2, E3 and $E_{v}$, based on a $4.0-1$ samples. Mean recovery ranged from 72.6 to $111.0 \%$ with relative standard deviation of $1.1-4.6 \%$ for surface water spiked, and $66.6 \%$ to $121.1 \%$ with relative standard deviation of $1.5-4.7 \%$ for effluent of WWTP spiked. Therefore, this method provided a robust solution for the determination of trace steroid estrogen in surface water and effluent of WWTP.

Acknowledgements This work was supported by Chinese Academy of Sciences (KZCX1-YW-06) and National Basic Research Program of China (2007CB407301). 


\section{References}

Alda, M. J. L., \& Barceló, D. (2001). Review of analytical methods for the determination of estrogens and progestogens in waste waters. Fresenius Journal of Analytical Chemistry, 371(4), 437-447.

Baronti, C., Curini, R., D’Ascenzo, G., Di, C. A., Gentili, A., \& Samperi, R. (2000). Monitoring natural and synthetic estrogens at activated sludge sewage treatment plants and in a receiving river water. Environmental Science \& Technology, 34(24), 5059-5066.

Beck, I. C., Bruhn, R., Gandrass, J., \& Ruck, W. (2005). Liquid chromatography-tandem mass spectrometry analysis of estrogenic compounds in coastal surface water of the Baltic Sea. Journal of Chromatography A, 1090(1-2), 98-106.

Benijts, T., Lambert, W., \& DeLeenheer, A. (2004). Analysis of multiple endocrine disruptors in environmental waters via wide-spectrum solid-phase extraction and dual-polarity ionization LC-ion trap-MS/MS. Analytical Chemistry, 76(3), 704-711.

Bila, D., Montalvao, A. F., Azevedo, D., \& Dezotti, M. (2007). Estrogenic activity removal of 17[beta]estradiol by ozonation and identification of byproducts. Chemosphere, 69(5), 736-746.

Chen, C. Y., Wen, T. Y., Wang, G. S., Cheng, H. W., Lin, Y. H., \& Lien, G. W. (2007). Determining estrogenic steroids in Taipei waters and removal in drinking water treatment using high-flow solid-phase extraction and liquid chromatography/tandem mass spectrometry. Science of the Total Environment, 378(3), 352-365.

Cui, C. W., Ji, S. L., \& Ren, H. Y. (2006). Determination of steroid estrogens in wastewater treatment plant of a contraceptives producing factory. Environmental Monitoring and Assessment, 121(1-3), 409-419.

Desbrow, C., Routledge, E. J., Brighty, G. C., Sumpter, J. P., \& Waldock, M. (1998). Identification of estrogenic chemicals in STW effluent. 1. Chemical fractionation and in vitro biological screening. Environmental Science \& Technology, 32(11), 1549-1558.

Fawell, J. K., Sheahan, D., James, H. A., Hurst, M., \& Scott, S. (2001). Oestrogens and oestrogenic activity in raw and treated water in Seven Trent Water. Water Research, 35(5), 1240-1244.

Feigelson, H. S., \& Henderson, E. B. (1996). Estrogens and breast cancer. Carcinogenesis, 17(11), 2279-2284.

Ferguson, P. L., Iden, C. R., McElroy, A. E., \& Brownawell, B. J. (2001). Determination of steroid estrogens in wastewater by immunoaffinity extraction coupled with HPLC-electrospray-MS. Analytical Chemistry, 73(16), 3890-3895.

Graham, J. D., Bain, L. D., Richer, K. J., Jackson, A. T., Tung, L., \& Horwitz, K. B. (2000). Thoughts on tamoxifen resistant breast cancer. Are coregulators the answer or just a red herring? Journal of Steroid Biochemistry and Molecular Biology, 74(5), 255-259.

Hernando, M. D., Mezcua, M., Gomez, M. J., Malato, O., Aguera, A., \& Fernandez, A. A. R. (2004). Comparative study of analytical methods involving gas chromatography-mass spectrometry after derivatization and gas chromatography-tandem mass spectrometry for the determination of selected endocrine disrupting compounds in wastewaters. Journal of Chromatography A, 1047(1), 129-135.

$\mathrm{Hu}$, J., Zhang, H., \& Chang, H. (2005). Improved method for analyzing estrogens in water by liquid chromatography-electrospray mass spectrometry. Journal of Chromatography A, 1070(1-2), 221-224.

Isobe, T., Shiraishi, H., Yasuda, M., Shinoda, A., Suzuki, H., \& Morita, M. (2003). Determination of estrogens and their conjugates in water using solid-phase extraction followed by liquid chromatography-tandem mass spectrometry. Journal of Chromatography A, 984(2), 195-202.

Jeannot, R., Sabik, H., Sauvard, E., Dagnac, T., \& Dohrendorf, K. (2002). Determination of endocrinedisrupting compounds in environmental samples using gas and liquid chromatography with mass spectrometry. Journal of Chromatography A, 974(1-2), 143-159.

Johnson, A. C., Belfroid, A., \& Di, C. A. (2000). Estimating steroid oestrogen inputs into activated sludge treatment works and observations on their removal from the effluent. The Science of The Total Environment, 256(2-3), 163-173.

Johnson, A. C., \& Sumpter, J. P. (2001). Removal of endocrine disrupting chemicals in activated sludge treatment works. Environmental Science \& Technology, 35(24), 4697-4703.

Kuster, M., Alda, M. J. L., \& Barceló, D. (2005). Estrogens and progestogens in wastewater, sludge, sediments, and soil (pp. 1-24). Berlin: Springer.

Kuster, M., Maria, J. L. A., \& Barcelo, D. (2004). Analysis and distribution of estrogens and progestogens in sewage sludge, soils and sediments. TrAC Trends in Analytical Chemistry, 23(10-11), 790-798.

Lai, K. M., Johnson, K. L., Scrimshaw, M. D., \& Lester, J. N. (2000). Binding of waterborne steroid estrogens to solid phases in river and estuarine systems. Environmental Science \& Technology, 34(18), 3890-3894.

Larsson, D. G. J., Adolfsson, E. M., Parkkonen, J., Pettersson, M., Berg, A. H., Olsson, P. E., et al. (1999). Ethinyloestradiol an undesired fish contraceptive? Aquatic Toxicology, 45(2-3), 91-97.

López, A. M. J., \& Barceló, D. (2001). Use of solidphase extraction in various of its modalities for sample preparation in the determination of estrogens and progestogens in sediment and water. Journal of Chromatography A, 938(1-2), 145-153.

Matejicek, D., Houserova, P., \& Kuban, V. (2007). Combined isolation and purification procedures prior to the high-performance liquid chromatographic-iontrap tandem mass spectrometric determination of estrogens and their conjugates in river sediments. Journal of Chromatography A, 1171(1-2), 80-89.

Maurício, R., Diniz, M., Petrovic, M., Amaral, L., Peres, I., Barceló, D., et al. (2006). A characterization of selected endocrine disrupter compounds in a Portuguese wastewater treatment plant. Environmental Monitoring and Assessment, 118(1-3), 75-87. 
Nakada, N., Shinohara, H., Murata, A., Kiri, K., Managaki, S., Sato, N., et al. (2007). Removal of selected pharmaceuticals and personal care products (PPCPs) and endocrine-disrupting chemicals (EDCs) during sand filtration and ozonation at a municipal sewage treatment plant. Water Research, 41(19), 4373.

Peck, M. R., Labadie, P., Minier, C., \& Hill, E. M. (2007). Profiles of environmental and endogenous estrogens in the zebra mussel Dreissena polymorpha. Chemosphere, 69(1), 1-8.

Quintana, J. B., Carpinteiro, J., Rodriguez, I., Lorenzo, R. A., Carro, A. M., \& Cela, R. (2004). Determination of natural and synthetic estrogens in water by gas chromatography with mass spectrometric detection. Journal of Chromatography A, 1024(1-2), 177-185.

Rodgers, G. T. P., Jobling, S., Morris, S., Kelly, C., Kirby, S., Janbakhsh, A., et al. (2000). Long-term temporal changes in the estrogenic composition of treated sewage effluent and its biological effects on fish. Environmental Science \& Technology, 34(8), 1521-1528.

Shareef, A., Parnis, C. J., Angove, M. J., Wells, J. D., \& Johnson, B. B. (2004). Suitability of N,O-bis (trimethylsilyl)trifluoroacetamide and N-(tert-butyldimethylsilyl)-N-methyltrifluoroacetamide as derivatization reagents for the determination of the estrogens estrone and 17[alpha]-ethinylestradiol by gas chromatography-mass spectrometry. Journal of Chromatography A, 1026(1-2), 295-300.

Solé, M., Porte, C., \& Barceló, D. (2001). Analysis of the estrogenic activity of sewage treatment works and receiving waters using vitellogenin induction in fish as a biomarker. TrAC Trends in Analytical Chemistry, 20(9), 518-525.

Sun, Q., Deng, S., Huang, J., Shen, G., \& Yu, G. (2008). Contributors to estrogenic activity in wastewater from a large wastewater treatment plant in Beijing, China. Environmental Toxicology and Pharmacology, 25(1), 20-26.

Ternes, T. A., Stumpf, M., Mueller, J., Haberer, K., Wilken, R. D., \& Servos, M. (1999). Behavior and occurrence of estrogens in municipal sewage treatment plants-I. Investigations in Germany, Canada and Brazil. The Science of The Total Environment, 225(1-2), 81-90.

Vethaak, A. D., Lahr, J., Schrap, S. M., Belfroid, A. C., Rijs, G. B. J., Gerritsen, A., et al. (2005). An integrated assessment of estrogenic contamination and biological effects in the aquatic environment of The Netherlands. Chemosphere, 59(4), 511-524.

Wang, Y., Hu, W., Cao, Z., Fu, X., \& Zhu, T. (2005). Occurrence of endocrine-disrupting compounds in reclaimed water from Tianjin, China. Analytical and Bioanalytical Chemistry, 383(5), 857-863.

Xiao, X., McCalley, D. V., \& McEvoy, J. (2001). Analysis of estrogens in river water and effluents using solidphase extraction and gas chromatography-negative chemical ionisation mass spectrometry of the pentafluorobenzoyl derivatives. Journal of Chromatography A, 923(1-2), 195-204.

Xu, X., Keefer, L. K., Waterhouse, D. J., Saavedra, J. E., Veenstra, T. D., \& Ziegler, R. G. (2004). Measuring seven endogenous ketolic estrogens simultaneously in human urine by high-performance liquid chromatography-mass spectrometry. Analytical Chemistry, 76(19), 5829-5836.

Xu, X., Roman, J. M., Veenstra, T. D., VanAnda, J., Ziegler, R. G., \& Issaq, H. J. (2006). Analysis of fifteen estrogen metabolites using packed column supercritical fluid chromatography-mass spectrometry. Analytical Chemistry, 78(5), 1553-1558.

Xu, X., Veenstra, T. D., Fox, S. D., Roman, J. M., Issaq, H. J., Falk, R., et al. (2005). Measuring fifteen endogenous estrogens simultaneously in human urine by high-performance liquid chromatography-mass spectrometry. Analytical Chemistry, 77(20), 6646-6654.

Yu, Z., Xiao, B., Huang, W., \& Peng, P. (2004). Sorption of steroid estrogens to soils and sediments. Environmental Toxicology and Chemistry, 23(3), 531539.

Zha, J., Sun, L., Zhou, Y., Spear, P., Ma, M., \& Wang, Z. (2008). Assessment of 17-ethinylestradiol effects and underlying mechanisms in a continuous, multigeneration exposure of the Chinese rare minnow (Gobiocypris rarus). Toxicology and Applied Pharmacology, 226(3), 298-308.

Zhang, H., \& Henion, J. (1999). Quantitative and qualitative determination of estrogen sulfates in human urine by liquid chromatography/tandem mass spectrometry using 96-well technology. Analytical Chemistry, 71(18), 3955-3964.

Zhou, Y., Wang, Z., \& Jia, N. (2007). Formation of multiple trimethylsilyl derivatives in the derivatization of 17[alpha]-ethinylestradiol with BSTFA or MSTFA followed by gas chromatography-mass spectrometry determination. Journal of Environmental Sciences, 19(7), 879-884.

Zuo, Y., \& Zhang, K. (2005). Suitability of N,O-bis (trimethylsilyl)trifluoroacetamide as derivatization reagent for the determination of the estrogens estrone and 17 [alpha]-ethinylestradiol by gas chromatography-mass spectrometry. Journal of Chromatography A, 1095(1-2), 201-202. 